\title{
THE ORAL TOLERANCE TO CONTACT ALLER- GENS IN PROSTHODONTIC BIOMATERIALS. CASE REPORTS
}

\author{
Iliyana Stoeva \\ Department of Allergology, Physiotherapy and Clinical radiology, \\ Faculty of Dental Medicine, Medical University-Plovdiv, Bulgaria
}

\begin{abstract}
Two cases of oral allergy to dental prosthodontic materials are presented, highlighting the interest of dosage of allergen and the clinical manifestation of contact allergy to prosthodontic dental materials. Symptoms appeared after placement of a new prosthesis of same material as the precedent one. These patients were able to tolerate the allergen in minor quantity and the increasing of the quantity interrupt the tolerance. These cases indicate a possible relationship between the oral contact allergy and the dosage of the allergen.
\end{abstract}

Key words: allergy, contact hypersensitivity, oral tolerance, prosthodontic materials

Reactions of hypersensitivity to prosthetic materials used in dentistry have still not been entirely explained. The etiology of a lesion in the oral cavity, developing after insertion of a restoration is frequently unclear and the opinion of clinicians varied (7).

The most common allergens in prosthetic materials are (meth)acrylates and metals. Occupational allergic contact dermatitis caused by (meth)acrylates is relatively common in dental stuff $(1,5,6,8)$, whereas denture material-induced reactions to acrylates in dental patients are less common (3, $7,9,11,17)$. Allergy to acrylates is a rare cause of stomatitis in dental patients because dental prosthesis and fillings contain acrylates present in polymerized form that is nonsensitizing (10). Contact dermatitis to metals especially to nickel is frequent but oral eruptions due to nickel allergy are rare $(4,7,13,15)$.

We report two cases of allergy to prosthetic dental materials appeared after placement of new prosthesis of same material as the precedent one.

\section{Case report 1:}

A 70-year-old woman developed an oral erythema and oedema of the tongue, lips and eyelids, which occurred when she used her new upper and lower dentures (Fig. 1). She had had an acrylic dental prosthesis for 10 years. New dentures were made because of extraction of some teeth. About 10 hours after placement of the new dentures she felt difficulties in breathing. Next day the symptoms aggravated and she asked an urgent treatment in Military Hospital, Sofia. After intramuscular injection of Methylprednisolon she was referred to our Department with a suspected allergic reaction to a denture. She had non personal history of allergy and no exposure to acrylics.

After the information of the dental personnel the new dentures and the precedent ones were made of Superacryl - a product of SpofaDental. According to the manufacturer, the components of the powder and liquid of the acrylic denture base material used by the patient were: powder containing polymethyl methacrylate and liquid containing MMA, and a cross-linking agent such as EGDMA.

One mouth later we performed the patch testing. Patch test was performed with the substances of dental screening series (Chemotechnique Diagnostics ${ }^{\circledR}$, Vellinge, Sweden) including MMA, EGDMA, TEGDMA, UDMA, 2HEMA, BISGMA, BP and N,N-Dimethyl-4-toluidine (Table 1) and with IQ Chambers ${ }^{\circledR}\left(\right.$ Chemotechnique Diagnostics ${ }^{\circledR}$, Vellinge, Sweden). The patches were removed after 2 days and read on day 3. Patch test results are shown in Table 1.

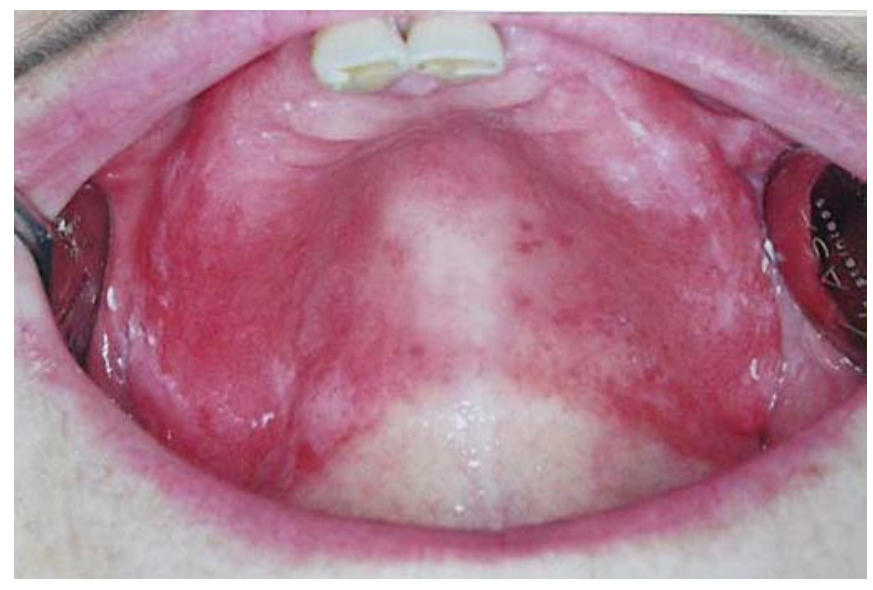

Fig. 1. Stomatitis contacta allergica 


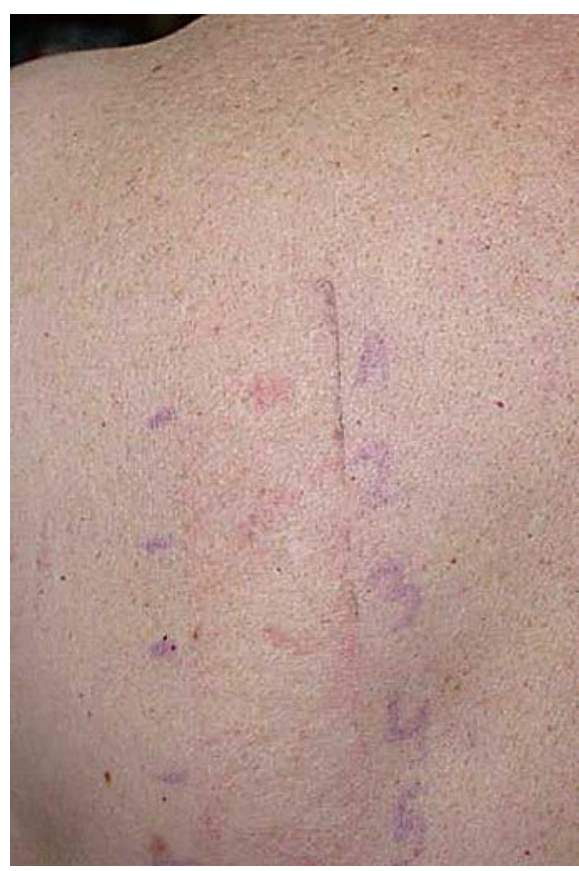

Fig. 2. Patch test results in patient 1

Table 1. Patch test results in patient 1

\begin{tabular}{|l|c|c|}
\hline Allergen & $\begin{array}{c}\text { \% } \\
\text { pet. }\end{array}$ & $\begin{array}{c}\text { Day } \\
\mathbf{3}\end{array}$ \\
\hline Methyl methacrylate (MMA) & 2.0 & ++ \\
\hline Ethyleneglycol dimethacrylate (EGDMA) & 2.0 & ++ \\
\hline Triethylene glycol dimethacrylate (TEGDMA) & 2.0 & + \\
\hline Urethane dimethacrylate (UDMA) & 2.0 & - \\
\hline 2-Hydroxyethyl methacrylate (2-HEMA) & 2.0 & + \\
\hline N,N-Dimethyl-4-toluidine & 5.0 & - \\
\hline $\begin{array}{l}\text { 2,2-bis(4-(2-Hydroxy-3-methacryloxypropoxy) } \\
\text { phenyl)propane (BIS-GMA) }\end{array}$ & 2.0 & - \\
\hline Benzoyl peroxide (BP) & 1.0 & - \\
\hline
\end{tabular}

\section{DISCUSSION:}

Acrylic materials are found in many dental products. Occupational allergic contact dermatitis due to acrylates in dental personnel is frequently reported. Sensitization in patients, however is rare.

We suppose our patient has been previously sensitized to her old dentures because no history of (meth)acrylates' exposition has been reported, as well the symptoms of allergy appeared very quickly after placement of the new dentures. Interestingly, our patient tolerated her old dentures made of same material. In contrast, new dentures were not tolerated. A study of Sadamory et al. (12) demonstrates that the residual monomer contents tended to be lower in dentures used for long periods than in those used for short periods. The leached out quantity of MMA residual monomer in the first days after oral placement of the denture is highest and most of residual monomer's loss occurs in the first 4 or 5 years, which may explain why the patient tolerated her old prosthesis. Also we suppose other condition for manifestation of the allergy, such as the polymerization cycle of the denture. The quantity of residual monomer depends on durability of curing cycle (2). Short curing cycle produces dentures with increased residual monomer which are more likely to induce mucosal reactions then dentures cured by a long curing cycle. Koutis and al (10) report a case of allergic contact stomatitis caused by acrylic monomer in a denture and the symptoms of the patient disappeared after prolonged boiling of the denture.

The present case demonstrates that severe contact allergy to acrylates in dental materials can occur in patients who have been previously sensitized to own denture.

\section{Case report 2:}

A 54-year-old woman presented with an itching and burning sensitization in the oral cavity for 1 month. The symptoms appeared approximately three days after placement of two cast post and core restorations for teeth 26 and 27. She was wearing two base cast bridges (upper and lower right hemiarch). She had been wearing the bridges during the past 10 years without any oral discomfort.

The physical examination showed an aphthous lesion in strong relationship with the post and core restorations and no local gingival or buccal reaction around base cast bridges.

The patient had a history of intolerance to jewelry for more than 30 years. Her dentist confirmed that the bridges were made of nickel-chrome dental alloy, as well the new post and core restorations.

Patch testing was performed with the substances of dental screening series (Chemotechnique Diagnostics ${ }^{\circledR}$, Vellinge, Sweden) and with IQ Chambers ${ }^{\circledR}$ (Chemotechnique Diagnostics ${ }^{\circledR}$, Vellinge, Sweden). The patches were removed after 2 days and read on day 3 . Positive patch test results are shown in Table 2.

Table 2. Positive patch test results in patient 2.

\begin{tabular}{|l|c|c|}
\hline Allergen & \% pet. & Day 3 \\
\hline Nickel sulfate hexahydrate & 5.0 & +++ \\
\hline Cobalt(II) chloride hexahydrate & 1.0 & ++ \\
\hline Palladium chloride & 2.0 & - \\
\hline
\end{tabular}




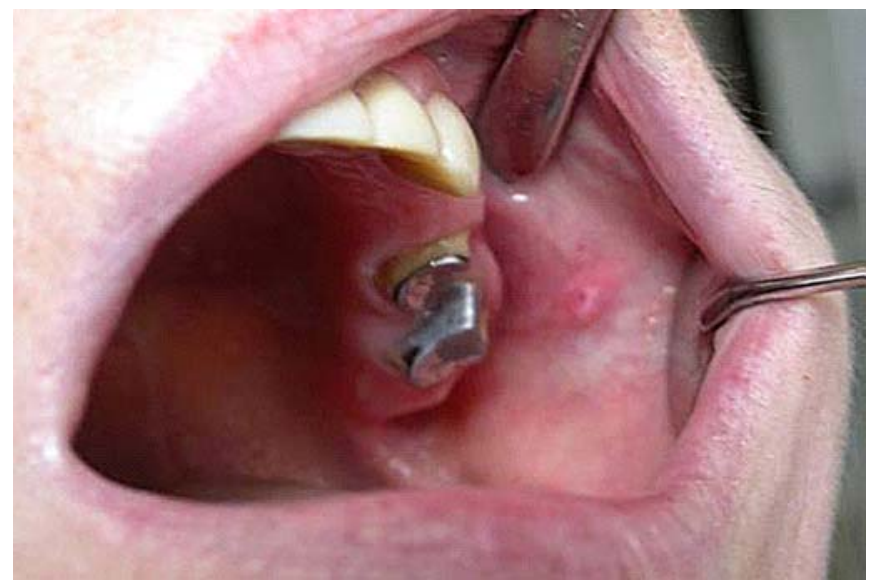

Fig. 3. An aphthous lesion in relationship with the cast post and core restorations

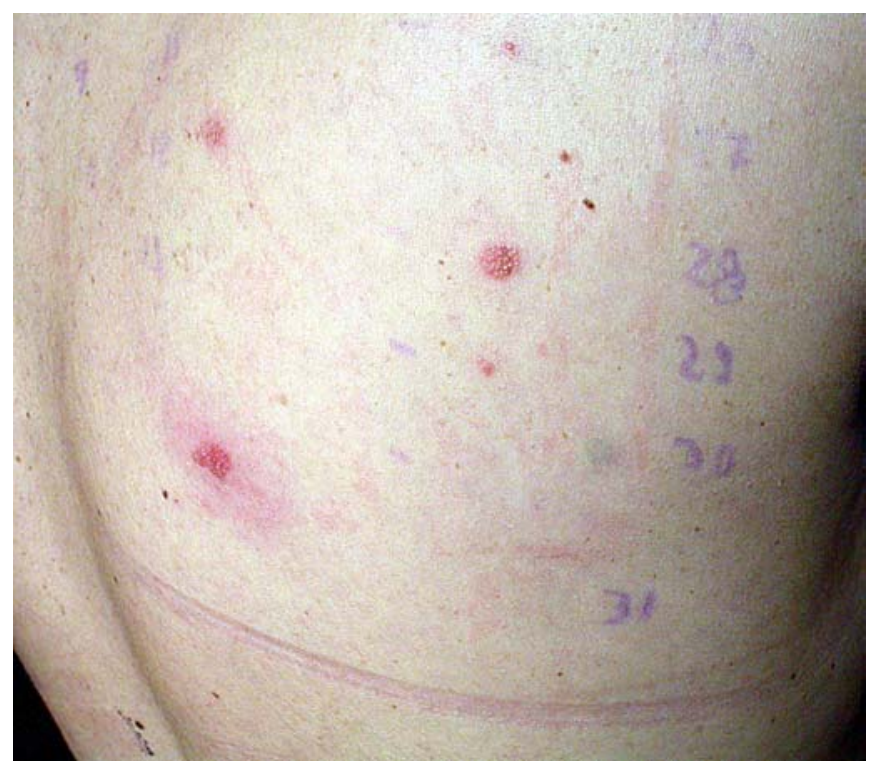

Fig. 4. Patch test results in patient 2

\section{DISCUSSION:}

The most common clinical presentation of intraoral contact dermatitis to nickel is a lichenoid plaque or erosion on the buccal mucosa adjacent to the offending antigen (4, $7,15,16)$. In our patient the clinical manifestation of hypersensitivity to nickel was an aphthous lesion appeared after placement of new cast post and core restorations and no signs before that although the two nickel-containing bridges were in the mouth.

Positive skin reactions to metals such as nickel are not necessarily associated with intraoral allergic reactions. It was observed that patients with a previous history of positive skin reactions to nickel did not develop local or systemic adverse effects in response to a nickel-containing dental alloy during an observation period of up to 15 years (14).

Shultz et al (13) reported a case of allergy to dental braces in previously sensitized patient but the symptoms appeared one year later. The author suggests that there is a threshold for nickel ion exposure which explains the lack of symptoms for a long period of time. Initially, there may have been oral tolerance to the nickel in the braces; with time, however, the leaching of the nickel from the braces may have become so great that the threshold for tolerance was surpassed, and the patient developed symptoms.

This case shows that an allergic reaction may appear after placement of new dental restoration, although the patient has been in contact with the allergen from other restoration for more years. Before the first prosthodontique treatment our patient was not asked for metal allergies, before the second she was neither. We found that our patient was aware of her allergy but did not consider that she might be exposed to same metals while receiving dental care.

\section{CONCLUSION:}

Classically, allergic responses are characterized by dose independence; that is, the body's reaction is independent of the dose applied. The two cases show that it is possible for very low levels of metal ions or acrylic monomers to be released in an allergic individual with no measurable allergic response. The absence of clinical signs of oral allergy in patients sensitive in patch test to a metal or acrylic monomer, although the metal or the acrylic monomer was a component of the dental prosthesis in their oral cavity, leads to dose-dependence of oral allergy. Only if these levels are exceeded does the concept of dose independence apply. 


\section{REFERENCES:}

1. Alanko K, P Susitaival, R Jolanki, L Kanerva. Occupational skin diseases among dental nurses. Contact Dermatitis 2004; 50:77-82.

2. Austin A, R Basker. Residual monomer levels in denture bases. Br Dent J 1982;153:424-426.

3. Bauer A, U. Wollina. Dentureinduced local and systemic reactions to acrylate. Allergy 1998; 53:722-723.

4. Dimova M, V Dosseva, I Stoeva. Clinical report of nickel allergy after metalceramic restorations. Problems of Dentistry 2005,XXXI(2);33-37.

5. Geukens S., A Goossens. Occupational contact allergy to (meth) acrylates. Contact Dermatitis 2001; 44:153159.

6. Hamann C, L De Paola, P Rodgers. Occupation-related allergies in dentistry. $\mathrm{J}$ Am Dent Assoc 2005, 136:500-510.

7. Ivanova I. Intraoral contact hypersensitivity to prosthodontic biomaterials. Dissertation 2008, Medical university, Faculty of dental medicine, Sofia, p.173.

8. Kanerva L, A. Lahtinen, J. Toikkanen, H. Forss, T. Estlander, P. Susitaival, R. Jolanki. Increase in occupational skin diseases of dental personnel. Contact Dermatitis 1999; 40:104-108.

9. Kanerva L, K Alanko, T Estlander. Allergic contact gingivostomatitis from a temporary crown made of methacrylates and epoxy diacrylates. Allergy 1999; 54 (12):1316-1321.

10. Koutis D, S Freeman. Allergic contact stomatitis caused by acrylic monomer in a denture. Australas J Dermatol 2001; 42:203-206.

11. Lunder T, M Rogl-Butina. Chronic urticaria from an acrylic dental prosthesis. Contact Dermatitis 2000; 43:232-233.

12. Sadamori S, H Kotani, T Hamada. The usage period of dentures and their residual monomer contents. J Prosthet Dent 1992; 68:374-376.
13. Shultz J, E Connelly, L Glesne, E Warshaw. Cutaneous and oral eruption from oral exposure to nickel in dental braces. Dermatitis 2004; 15:154-157.

14. Spiechowicz E, P Glanz, T. Axell, P. Grochowski. A long term follow-up of allergy to nickel among fixed prosthesis wearers. Eur J Prosthodont Dent 1999; 7:41-44.

15. Stoeva I. Allergic reactions to dental alloys in prosthetic dentistry. Problems of Dentistry 2006, XXXII:64-69.

16. Stoeva I, A. Kisselova. Prevalence of metal sensitivity in symptomatic patients with dental alloy restorations and the relation to the clinical manifestations. Biotechnol\&Biotechnol EQ 2010; 24(2): 1870-1873.

17. Vilaplana J, C Romaguera, F Cornellana. Contact dermatitis and adverse oral mucous membrane reactions related to the use of dental prosthesis. Contact Dermatitis 1994; 30:80-84.

\section{Adrress for correspondence:}

Iliyana Stoeva

Department of Allergology, Phisiotherapy and Clinical Radiology, Faculty of Dental Medicine, Medical University - Plovdiv, Bulgaria 3, Hristo Botev bulv., 4000 Plovdiv, Bulgaria e-mail: stoeva_iliana@abv.bg 